\title{
Riboflavin Supplementation Improves Energy Metabolism in Mice Exposed to Acute Hypoxia
}

\author{
Y. P. WANG ${ }^{1,2}$, J. Y. WEI ${ }^{1}$, J. J. YANG ${ }^{1}$, W. N. GAO ${ }^{1}$, J. Q. WU ${ }^{1}$, C. J. GUO ${ }^{1}$ \\ ${ }^{1}$ Department of Nutrition, Institute of Health and Environmental Medicine, Tianjin, China, \\ ${ }^{2}$ Department of Nutrition, Ninghe Hospital, Tianjin, China
}

Received September 27, 2013

Accepted November 21, 2013

On-line February 24, 2014

\section{Summary}

This study investigated the effects of riboflavin on energy metabolism in hypoxic mice. Kunming mice were fed diets containing riboflavin at doses of $6,12,24$ and $48 \mathrm{mg} / \mathrm{kg}$, respectively for 2 weeks before exposure to a simulated altitude of $6000 \mathrm{~m}$ for $8 \mathrm{~h}$. Changes of riboflavin status and energy metabolism were assessed biochemically. Simultaneously, a ${ }^{1} \mathrm{H}$ nuclear magnetic resonance (NMR) based metabolomic technique was used to track the changes of plasma metabolic profiling. It was found that the content of hepatic riboflavin was decreased and erythrocyte glutathione activation coefficient was elevated significantly under hypoxic condition. Meanwhile, increased plasma pyruvate, lactate, $\beta$-hydroxybutyrate and urea, as well as decreased plasma carnitine were observed. Riboflavin supplementation improved riboflavin status remarkably in hypoxic mice and decreased plasma levels of pyruvate, free fatty acids and $\beta$-hydroxybutyrate significantly. Plasma carnitine was increased in response to riboflavin supplementation. Results obtained from ${ }^{1} \mathrm{H}$ NMR analysis were basically in line with the data from biochemical assays and remarkable changes in plasma taurine, choline and some other metabolites were also indicated. It was concluded that riboflavin requirement was increased under acute hypoxic condition and riboflavin supplementation was effective in improving energy metabolism in hypoxic mice.

\section{Key words}

Hypoxia • Riboflavin • Energy metabolism • ${ }^{1} \mathrm{H}$ NMR analysis

\section{Corresponding author}

Changjiang Guo, Institute of Health and Environmental Medicine, No1 Dali Road, Tianjin 300050, P. R. China. Fax: +86-2223314818. E-mail: guo_tj@yahoo.com

\section{Introduction}

Riboflavin is a precursor of flavin mononucleotide (FMN) and flavin adenine dinucleotide (FAD), and serves as coenzymes for numerous oxidases, reductases and dehydrogenases in metabolic processes. Riboflavin deficiency results in low FMN and FAD contents in the cell and reduced activity of a series of flavin-containing enzymes (Powers 2003, Lienhart et al. 2013). It had been confirmed that mitochondrial $\beta$ oxidation was impaired significantly in response to riboflavin deficiency, because several flavin-containing enzymes, such as acyl-CoA dehydrogenase, work in the $\beta$-oxidation (Brady and Hoppel 1985). Riboflavin also plays a role in glutathione synthesis since FAD is a cofactor for glutathione reductase. The erythrocyte glutathione reductase activation coefficient (EGRAC) is frequently used as a sensitive maker in the assessment of riboflavin status (Hoey et al. 2009). In addition, riboflavin is required for methylenetetrahydrofolate reductase (MTHFR) and plays an important role in homocysteine metabolism, especially in individuals with the MTHFR 677 TT genotype (McNulty et al. 2006).

It has been well documented that acute hypoxia impacts significantly on nutritional status, resulting in anorexia, weight loss and altered energy metabolism (Guilland and Klepping 1985, Simon-Schnass 1992). Since energy requirement is elevated at high altitude, it is generally proposed that the requirement of the $\mathrm{B}$ vitamins involved in energy metabolism is also increased (Butterfield 1999). Our previous studies showed that a nutritional preparation containing $B$ vitamins could 
significantly prolong survival time in mice exposed to acute hypoxia and improve cardiac and pulmonary function of young adults at high altitude (Guo et al. 2004, Wang et al. 2005). Since riboflavin is one of B vitamins playing active roles in energy metabolism, it is important to explore its requirement at high altitude. To our knowledge, no study has been carried out experimentally so far yet to probe into the effects of riboflavin supplementation on energy metabolism under hypoxic condition.

In the present study, changes of riboflavin status were assessed in response to acute hypoxia and the effects of riboflavin supplementation were evaluated biochemically in mice. Meanwhile, a ${ }^{1} \mathrm{H}$ nuclear magnetic resonance (NMR) based metabolomic technique was used to investigate the effects of riboflavin supplementation on plasma metabolic profiling in hypoxic mice. The purpose of this study was to investigate the changes of riboflavin status under the acute hypoxia condition and provide experimental evidences that riboflavin requirement is increased after exposure to acute hypoxia.

\section{Materials and Methods}

\section{Animal treatments}

Thirty-five male Kunming mice, weighting 14-

$16 \mathrm{~g}$, were purchased from the Laboratory Animal Center, Academy of Military Medical Sciences (Beijing, China) and housed in a well ventilated room. Throughout the experimental period, all mice were allowed free access to food and tap water. The ambient temperature was maintained between $20^{\circ} \mathrm{C}$ and $24^{\circ} \mathrm{C}$ and the humidity between $40 \%$ and $60 \%$. All procedures were performed in accordance with the current Chinese legislation on the care and use of laboratory animals and approved by the Department of Scientific Management of the institute.

After being acclimatized on a basic diet (AIN-93 diet) (Reeves et al. 1993) for 5 days, mice were divided randomly into the normoxia control, hypoxia control and hypoxia plus riboflavin-supplemented groups. The mice in the normoxia or hypoxia control were fed continuously the basic diet, while those in three riboflavin supplemented groups received diets supplemented with riboflavin at doses of 12,24 and $48 \mathrm{mg} / \mathrm{kg}$, respectively. The supplemented riboflavin was 2, 4 and 8 times the level of riboflavin $(6 \mathrm{mg} / \mathrm{kg})$ contained in the basic diet. The experiment lasted 2 weeks. Finally, all mice except those in the normoxia control were exposed to a simulated altitude of $6000 \mathrm{~m}$ for $8 \mathrm{~h}$. The procedure was carried out in a hypoxia chamber as follows. First, all mice were elevated to $5000 \mathrm{~m}$ at the speed of $1000 \mathrm{~m} / \mathrm{min}$, and stopped for $3 \mathrm{~min}$, and then to $6000 \mathrm{~m}$ at the speed of $500 \mathrm{~m} / \mathrm{min}$. After $8 \mathrm{~h}$ exposure at $6000 \mathrm{~m}$, the mice returned to $5000 \mathrm{~m}$ at the speed of $500 \mathrm{~m} / \mathrm{min}$, and stopped for $3 \mathrm{~min}$ and then to the sea level at the speed of $1000 \mathrm{~m} / \mathrm{min}$. The blood samples were collected immediately from the orbital veins after ether anesthetization and anti-coagulated with heparin. The plasma was prepared after centrifuged at $8000 \mathrm{~g}$ for $10 \mathrm{~min}$ and stored at $-20{ }^{\circ} \mathrm{C}$ prior to analysis.

\section{Biochemical assays}

Plasma and hepatic riboflavin was determined by high performance liquid chromatography procedures described by Wei et al. (2006) and Ndaw et al. (2000), respectively. A modified assay developed by $\mathrm{Gu}$ et al. (1982) was used for measurement of EGRAC. Plasma glucose, lactate, free fatty acids, $\beta$-hydroxybutyrate and urea were assayed by using corresponding assay kits purchased from Nanjing Jiancheng Bioengineering Institute (Nanjing, China), respectively. All measurements were performed strictly in line with the instructions attached.

\section{${ }^{l} H$ NMR analysis}

Five plasma samples from each group were selected randomly for ${ }^{1} \mathrm{H}$ NMR analysis. Sample preparation and NMR analysis were performed as described elsewhere with minor modifications (Lenz et al. 2003, Wu et al. 2012). Briefly, plasma samples of $180 \mu \mathrm{l}$ were mixed with $100 \mu \mathrm{l}$ of $1.0 \mathrm{mmol} / \mathrm{l} \mathrm{3}$ (trimethylsilyl)-propionic-(2,2,3, 3,-d4)-acid sodium (TSP) in $320 \mu \mathrm{D}_{2} \mathrm{O}$, shaken vigorously, and centrifuged at $13000 \times \mathrm{g}$ for $10 \mathrm{~min}$. The aliquots of the resulting supernatant $(550 \mu \mathrm{l})$ were placed in $5 \mathrm{~mm}$ NMR tubes. $\mathrm{D}_{2} \mathrm{O}$ and TSP provided the deuterium lock signal for the NMR spectrometer and chemical shift reference $(\delta 0.0)$, respectively.

${ }^{1} \mathrm{H}$ NMR spectra of all samples were obtained at $599.69 \mathrm{MHz}$ on a Varian INOVA $600 \mathrm{NMR}$ spectrometer. One-dimensional spectra were acquired using a standard NOESY pulse sequence with water suppression during a relaxation delay of $2 \mathrm{~s}$ and a mixing time of $150 \mathrm{~ms}$. Sixty-four free reduction decays (FIDs) were collected into $64 \mathrm{~K}$ data points with a spectral width of $7002.8 \mathrm{~Hz}$, an acquisition time of $4.68 \mathrm{~s}$, and a total pulse recycle delay of $6.68 \mathrm{~s}$. The FIDs were multiplied 
by an exponential weighting function corresponding to a line broadening of $0.5 \mathrm{~Hz}$ before Fourier transformation.

\section{Statistical analysis}

The data of biochemical assays were expressed as mean \pm standard deviation and evaluated by one-way ANOVA. Differences were considered significant at $\mathrm{P}<0.05$.

The NMR integral data were imported into SIMCA-P (version 10.04, Umetrics Umeå, Sweden) for multivariate analysis. The Carr-Purcell-Meiboom-Gill (CPMG) data were mean-centered and Pareto-scaled, while the longitudinal eddy-current delay (LED) data were only mean-centered prior to analysis. Principal components analysis (PCA) or partial least squaresdiscriminant analysis (PLS-DA) was used to detect metabolic differences between groups. In case that group separation was not satisfied, the data were preprocessed using orthogonal signal correction (OSC) to remove the variations not correlated to the group membership and further subject to PCA or PLS-DA. The results were visualized by two-dimensional score plots representing the distribution of samples, as well as the corresponding loading plots providing information on the contribution of each variable to the pattern in the scores plots.

Table 1. Changes of riboflavin level in plasma and liver, and EGRAC among different groups after exposed to acute hypoxia.

\begin{tabular}{lccc}
\hline Groups & $\begin{array}{c}\text { Plasma riboflavin } \\
(\boldsymbol{\mu m o l} / \mathbf{l})\end{array}$ & $\begin{array}{c}\text { Liver riboflavin } \\
(\mathbf{m g} / \mathbf{1 0 0} \mathbf{g ~ F W})\end{array}$ & EGRAC \\
\hline Normoxia & $124.6 \pm 16.2$ & $0.35 \pm 0.12$ & $1.02 \pm 0.03$ \\
Hypoxia & $127.7 \pm 17.4$ & $0.19 \pm 0.04^{* *}$ & $1.06 \pm 0.02^{*}$ \\
Hypoxia plus 2 times $R$ & $118.8 \pm 22.3$ & $0.23 \pm 0.10^{*}$ & $1.04 \pm 0.03$ \\
Hypoxia plus 4 times $R$ & $117.0 \pm 9.9$ & $0.20 \pm 0.04^{*}$ & $1.04 \pm 0.04$ \\
Hypoxia plus 8 times $R$ & $141.4 \pm 26.8$ & $0.25 \pm 0.07$ & $1.03 \pm 0.02$ \\
\hline
\end{tabular}

Values are mean $\pm S D, n=7$. R: riboflavin. EGRAC: erythrocyte glutathione reductase activation coefficient. Significant difference from the normoxia: * $\mathrm{p}<0.05, * * \mathrm{p}<0.01$

Table 2. Changes of plasma glucose, pyruvate, lactate, free fatty acids, $\beta$-hydroxybutyrate and carnitine levels among different groups after exposed to acute hypoxia.

\begin{tabular}{|c|c|c|c|c|c|c|c|}
\hline Groups & $\begin{array}{l}\text { Glucose } \\
(\mathrm{mmol} / \mathrm{l})\end{array}$ & $\begin{array}{c}\text { Pyruvate } \\
(\mu \mathrm{mol} / \mathrm{l})\end{array}$ & $\begin{array}{l}\text { Lactate } \\
(\mathrm{mmol} / \mathrm{l})\end{array}$ & $\begin{array}{c}\text { Free fatty } \\
\text { acids } \\
(\mu \mathrm{mol} / \mathrm{l})\end{array}$ & $\begin{array}{c}\beta \text {-Hydroxy- } \\
\text { butyrate } \\
\text { (nmol/l) }\end{array}$ & $\begin{array}{c}\text { Carnitine } \\
(\mu \mathrm{mol} / \mathrm{l})\end{array}$ & $\begin{array}{c}\text { Urea } \\
(\mathrm{mmol} / \mathrm{l})\end{array}$ \\
\hline \multirow{2}{*}{ Normoxia } & 13.55 & 0.39 & 3.70 & 859.04 & 4.31 & 9.28 & 5.16 \\
\hline & \pm 2.75 & \pm 0.11 & \pm 2.82 & \pm 390.27 & \pm 0.36 & \pm 3.04 & \pm 0.90 \\
\hline \multirow{2}{*}{ Hурохіа } & 14.03 & 0.57 & 6.35 & 973.91 & 5.38 & 2.82 & 9.15 \\
\hline & \pm 2.79 & $\pm 0.07 * *$ & $\pm 2.01 *$ & \pm 259.39 & $\pm 0.51 * *$ & $\pm 1.89^{*}$ & $\pm 2.65^{* *}$ \\
\hline Hypoxia plus & 14.13 & 0.59 & 5.37 & 693.88 & 5.21 & 2.10 & 9.04 \\
\hline 2 times $R$ & \pm 1.12 & $\pm 0.05 * *$ & $\pm 4.05^{*}$ & \pm 292.34 & $\pm 0.26^{* *}$ & $\pm 0.52 *$ & $\pm 1.68 * *$ \\
\hline Hypoxia plus & 12.51 & 0.52 & 7.82 & 788.72 & 4.96 & 4.92 & 9.50 \\
\hline 4 times $R$ & \pm 1.72 & $\pm 0.09 *$ & $\pm 2.42 * *$ & \pm 339.81 & $\pm 0.16^{* *}$ & \pm 1.31 & $\pm 2.75 * *$ \\
\hline Hypoxia plus & 12.63 & 0.48 & 7.39 & 372.43 & 4.93 & 6.86 & 9.40 \\
\hline 8 times $R$ & \pm 1.23 & $\pm 0.05^{*}$ & $\pm 1.44 * *$ & $\pm 127.28 * \# \#$ & $\pm 0.05 * * \#$ & \pm 1.22 & $\pm 1.71 * *$ \\
\hline
\end{tabular}

Values are mean $\pm S D, n=7$. R: riboflavin. Significant difference from the normoxia: $* p<0.05, * * p<0.01$. Significant difference from the hypoxia: \# $p<0.05$, \#\# $p<0.01$ 
E

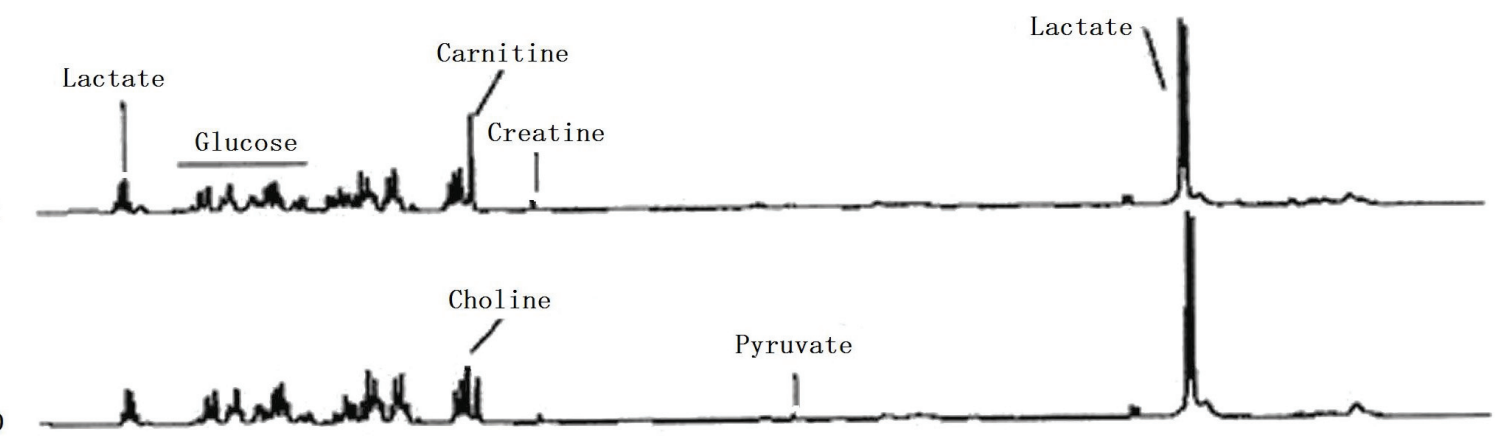

C

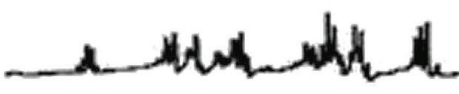

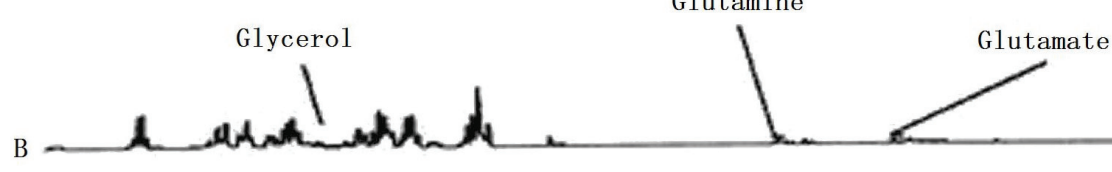

Isoleucine/Leucine
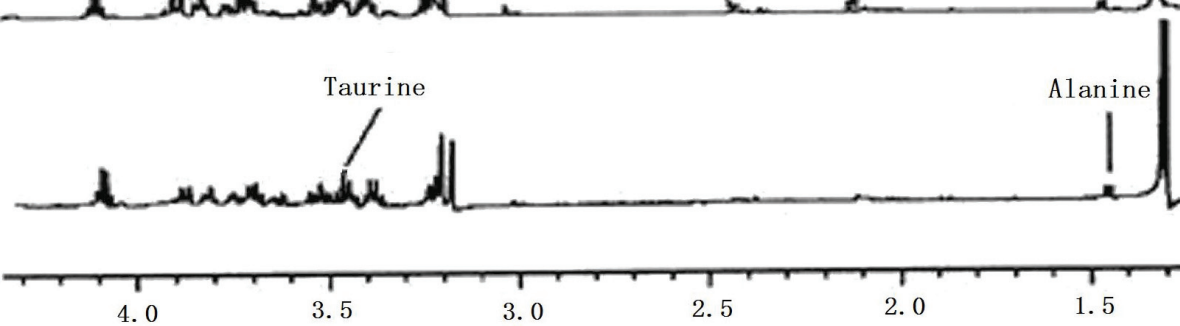

2.5

2. 0

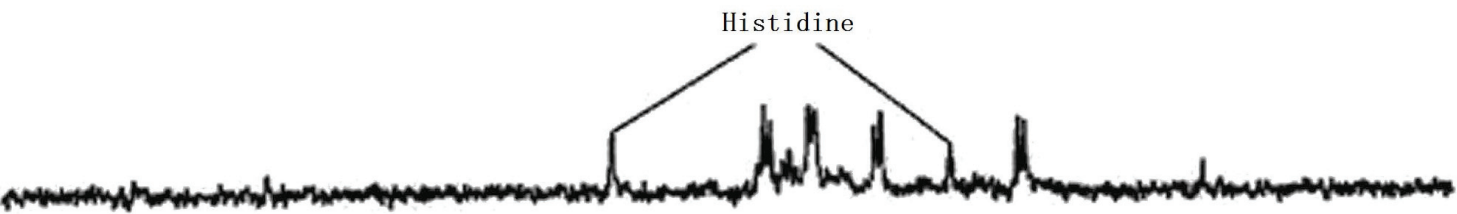

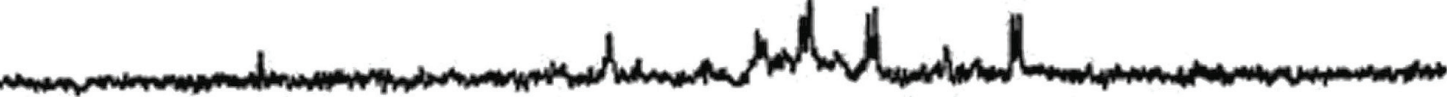

Phenylalanine

C

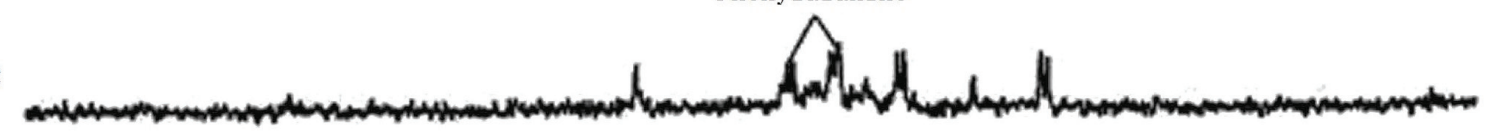

B

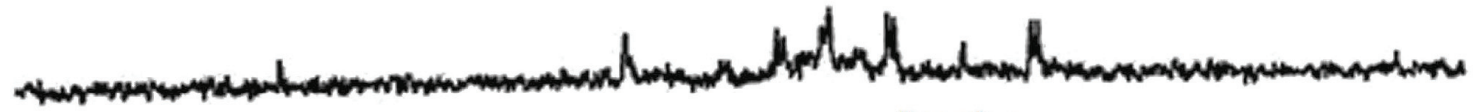

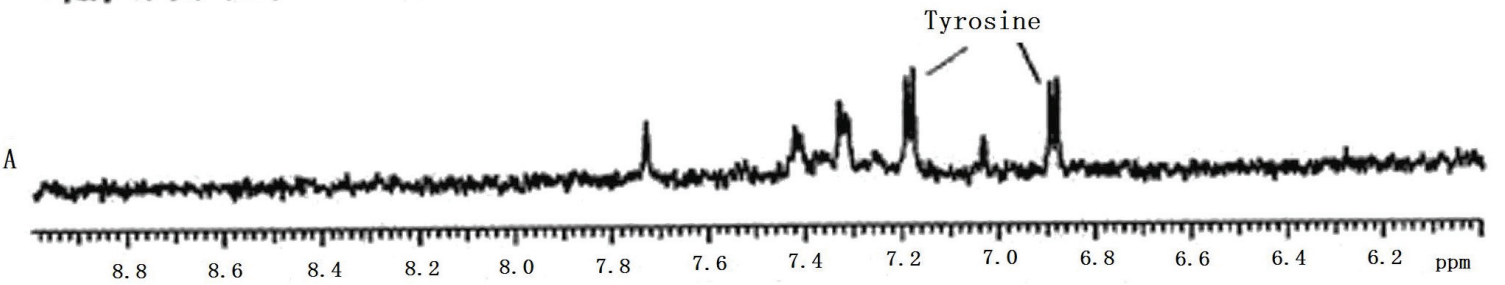

Fig. 1. Representative ${ }^{1} \mathrm{H}$ NMR spectra of plasma samples. The vertical scale in the aromatic region (bottom) was magnified four times compared with that in the alphatic region (top). A: normoxia control; B: hypoxia control; C: hypoxia plus 2 times riboflavinsupplemented group; D: hypoxia plus 4 times riboflavin-supplemented group; E: hypoxia plus 8 times riboflavin-supplemented group 


\section{Results}

\section{Riboflavin status}

As indicated in Table 1, plasma riboflavin level did not change significantly in mice after exposure to acute hypoxia compared to the normoxia control. Supplementation of 8 times riboflavin increased plasma riboflavin level slightly without statistic significance.

A significant decrease in hepatic content of riboflavin was observed in the acute hypoxia group $(\mathrm{P}<0.01)$. Riboflavin supplementation prevented the decline in hepatic content of riboflavin after acute hypoxia treatment. The acute hypoxia plus 8 times riboflavin supplemented group was not different statistically from the normoxia control in the content of hepatic riboflavin (Table 1).

After exposure to acute hypoxia, EGRAC was raised significantly $(\mathrm{P}<0.05)$ as compared to the normoxia control. A decrease trend was noted in EGRAC in response to 2 times, 4 times and 8 times riboflavin supplementation in mice treated with acute hypoxia, indicating an improved riboflavin status (Table 1).

Plasma levels of glucose, pyruvate, lactate, free fatty acids, $\beta$-hydroxybutyrate, carnitine and urea

Compared to the normoxia group, plasma glucose did not change significantly in mice treated with acute hypoxia. No significant change was also found for plasma glucose after riboflavin supplementation. However, plasma pyruvate was increased remarkably after acute hypoxia exposure $(\mathrm{P}<0.01)$ and decreased in response to riboflavin supplementation in a dose dependent manner. On the other hand, plasma lactate was increased significantly after acute hypoxia exposure $(\mathrm{P}<0.05)$, and more increase was noted after riboflavin treatment (Table 2).

Plasma free fatty acids did not change significantly in mice subjected to acute hypoxia. When riboflavin supplementation was increased to 8 times, plasma free fatty acids were decreased significantly as compared to the normoxia control $(\mathrm{P}<0.05)$. Plasma $\beta$ hydroxybutyrate was increased significantly $(\mathrm{P}<0.01)$ after acute hypoxia exposure and responded inversely to riboflavin supplementation. Moreover, plasma carnitine was decreased significantly in mice after exposure to acute hypoxia $(\mathrm{P}<0.05)$. Riboflavin treatment increased plasma carnitine in a dose dependent manner. No significant difference was found in plasma carnitine level between the normoxia group and acute hypoxia plus
8 times riboflavin supplemented group (Table 2).

Plasma urea was significantly increased after acute hypoxia treatment $(\mathrm{P}<0.01)$. No significant change was observed after riboflavin supplementation (Table 2).

\section{Plasma ${ }^{1} H$ NMR spectra}

In the aliphatic regions (0.8-4.5 ppm, Fig. 1 top) of the ${ }^{1} \mathrm{H}$ NMR spectra, it was found by visual inspection that signals of some endogenous metabolite changed in response to acute hypoxia exposure and riboflavin treatment. Compared to the normoxia group, there was an obvious decrease in carnitine level in the acute hypoxia group and a recovery was noted upon riboflavin supplementation. In the aromatic region (6.6-8.6 ppm, Fig. 1 bottom), visual changes was also observed for some amino acids, such as histidine, tyrosine and phenylalanine.
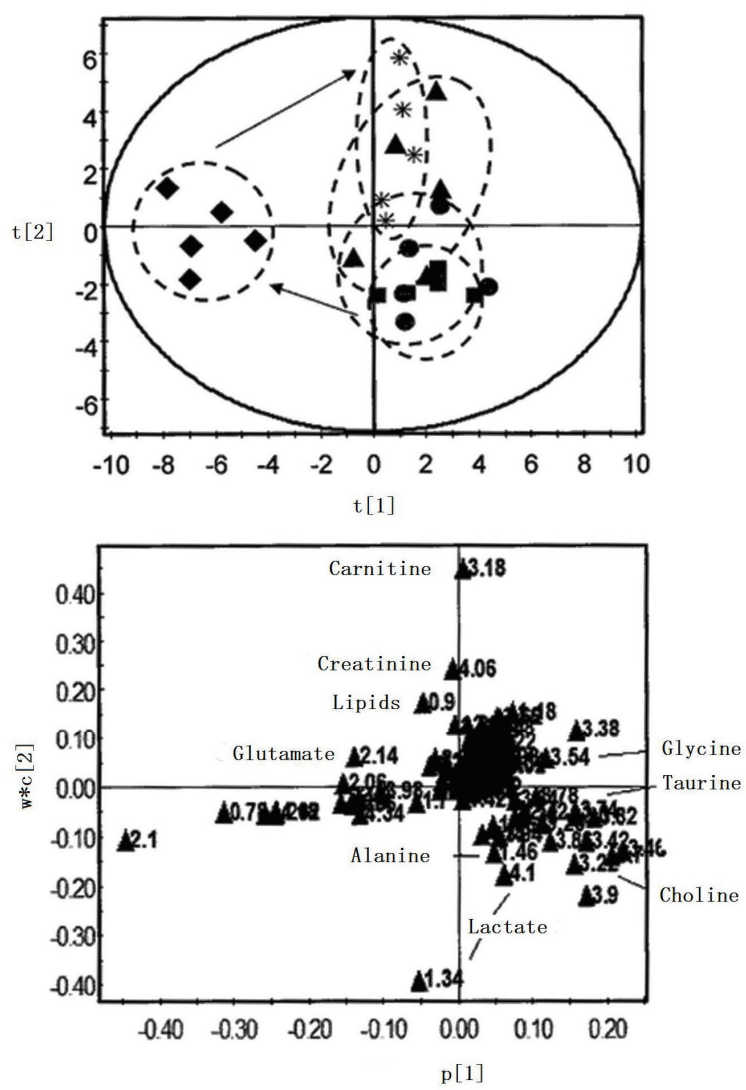

Fig. 2. Scores plot (top) and loadings plot (bottom) derived from ${ }^{1} \mathrm{H}$ NMR spectra of plasma samples after orthogonal signal correction (OSC) and partial least squares-discriminant analysis (PLS-DA). In the scores plot, each point represents a single mouse plasma sample and $\mathrm{t}[1], \mathrm{t}[2]$ indicate the scores on principal component 1 and 2 , respectively. The metabolites responsible for the variance in the scores plot are indicated in the loadings plot by their distance from the origin and $\mathrm{p}[1], \mathrm{w}^{*} \mathrm{c}[2]$ represent the weights on principal component 1 and 2, respectively. $\mathbf{\Delta}$ : normoxia control; $\mathbf{m :}$ hypoxia control; 0: hypoxia plus 2 times riboflavin-supplemented group; ४: hypoxia plus 4 times riboflavin-supplemented group; $*$ : hypoxia plus 4 times riboflavin-supplemented group 
In order to detect more subtle metabolic differences, pattern recognition techniques were applied. The PCA scores plot of pc1 versus pc 2 of all plasma samples from five groups showed that five clusters were presented, indicating that the metabolic trajectory of the acute hypoxia group moved away from the normoxia group. Meanwhile, the metabolic trajectory of the 4 times riboflavin supplemented group was clearly separated from the acute hypoxia group. When 8 times riboflavin was supplemented, the metabolic trajectory moved close to the normoxia group (Fig. 2 top). The corresponding loadings plot revealed that the separation between different groups was mainly attributed to the changes of following metabolites: lipids $(\delta 0.9)$, lactate $(\delta 1.34,4.1)$, alanine ( $\delta 1.46)$, glutamate $(\delta 2.14)$, choline $(\delta 3.22)$, taurine $(\delta 3.42)$, carnitine $(\delta 3.18)$, glycine $(\delta 3.54)$ and creatinine ( $\delta 4.06)$ (Fig. 2 bottom).
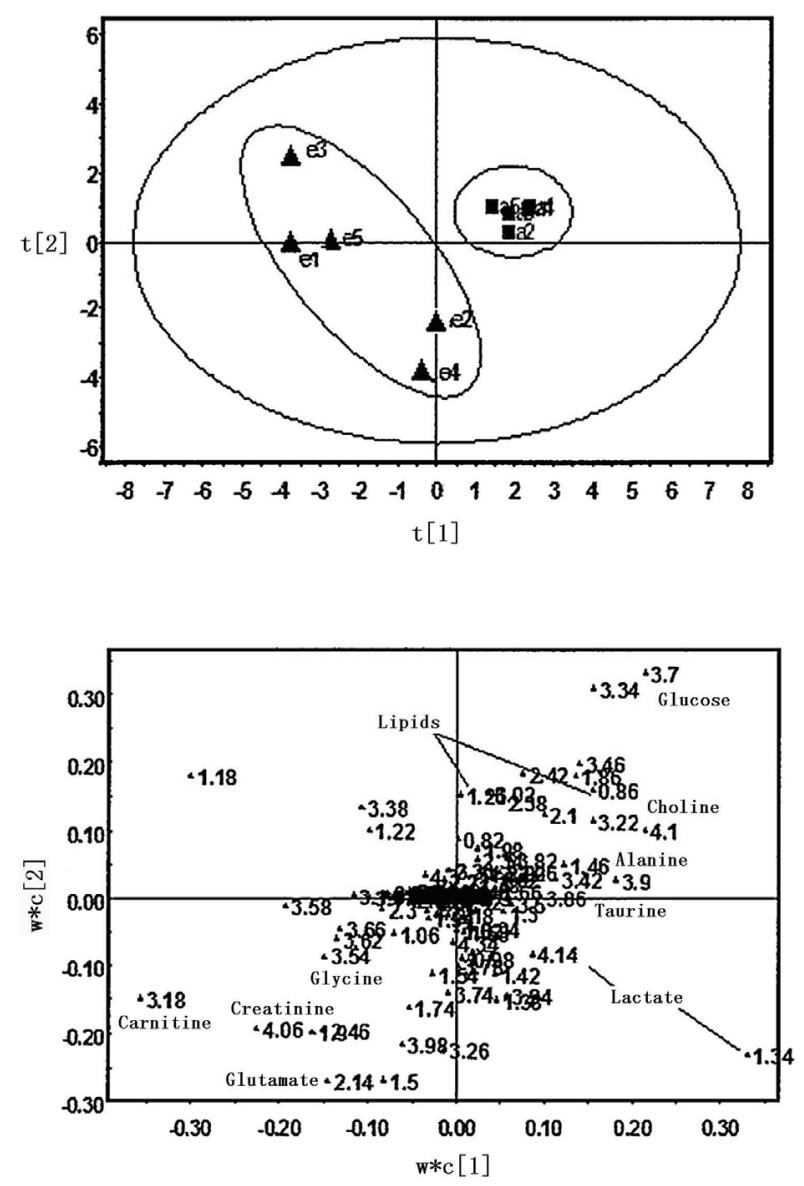

Fig. 3. Scores plot (top) and loadings plot (bottom) derived from ${ }^{1} \mathrm{H}$ NMR spectra of plasma samples from the normoxia $(\boldsymbol{\Delta})$ and hypoxia ( $\mathbf{a})$ groups after partial least squares-discriminant analysis (PLS-DA). In the scores plot, each point represents a single mouse plasma sample and $\mathrm{t}[1], \mathrm{t}[2]$ indicate the scores on principal component 1 and 2, respectively. The metabolites responsible for the variance in the scores plot are indicated in the loadings plot by their distance from the origin and $\mathrm{w}^{*} \mathrm{C}[1]$, $\mathrm{w}^{*} \mathrm{C}[2]$ represent the weights on principal component 1 and 2 , respectively.
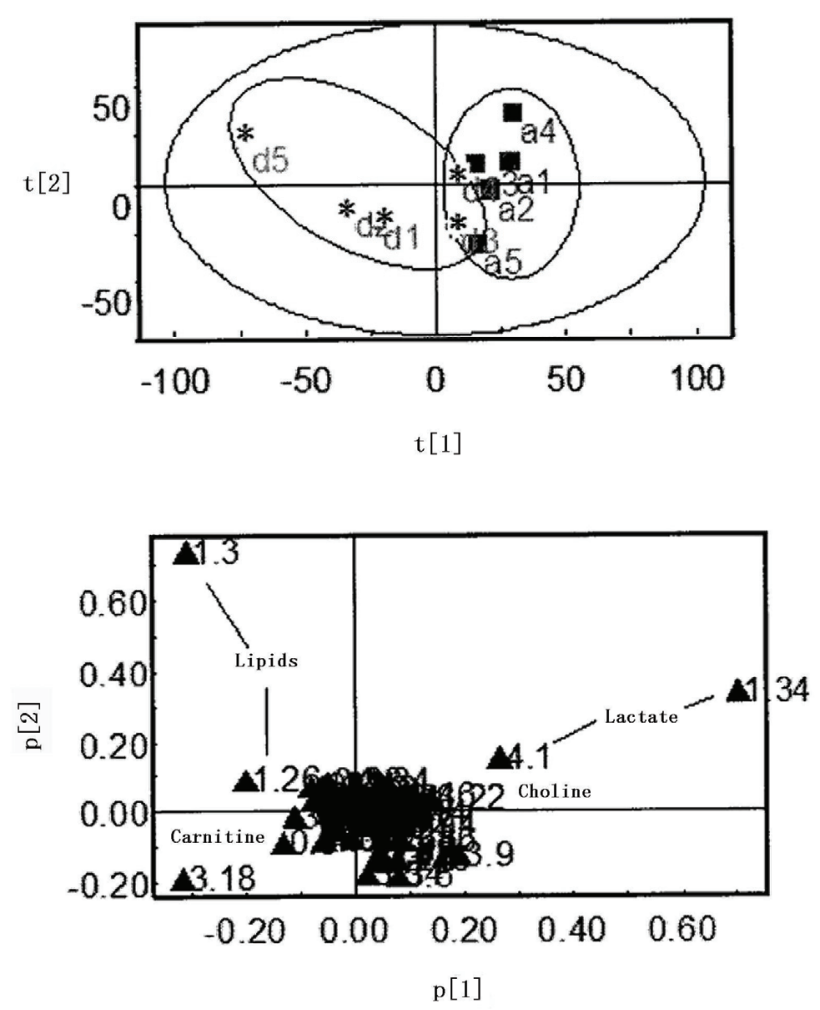

Fig. 4. Scores plot (top) and loadings plot (bottom) derived from ${ }^{1} \mathrm{H}$ NMR spectra of plasma samples from the hypoxia ( $\left.\mathbf{a}\right)$ and hypoxia plus 8 times riboflavin supplemented $(*)$ groups after principal components analysis (PCA). In the scores plot, each point represents a single mouse plasma sample and $\mathrm{t}[1]$, $\mathrm{t}[2]$ indicate the scores on principal component 1 and 2, respectively. The metabolites responsible for the variance in the scores plot are indicated in the loadings plot by their distance from the origin and $\mathrm{p}[1], \mathrm{p}[2]$ represent the weights on principal component 1 and 2 , respectively.

Further analysis was carried out either between the normoxia group and acute hypoxia group or between the acute hypoxia group and 8 times riboflavin supplemented group. The PCA scores plot of pc1 versus pc2 showed two clusters of plasma samples related to the normoxia and acute hypoxia groups (Fig. 3 top). The corresponding loadings plot suggested that the separation of metabolic pattern of the two groups was due to the changes of following metabolites: lipids $(\delta 0.9)$, lactate $(\delta 1.34,4.1)$, alanine $(\delta 1.46)$, glutamate $(\delta 2.14)$, pyruvate $(\delta 2.38)$, glutamine $(\delta 2.42)$, glucose $(\delta 3.0-4.0)$, carnitine $(\delta 3.18)$, choline $(\delta 3.22)$, taurine $(\delta 3.42)$ and glycine ( 83.54$)$ (Fig. 3 bottom). The PCA scores plot of pc1 versus pc 2 derived from the acute hypoxia and 8 times riboflavin supplemented groups indicated that two groups were separated (Fig. 4 top). The corresponding loadings plot suggested that the separation of metabolic pattern of the two groups was due to the changes of following metabolites: lipids $(\delta 0.9)$, lactate $(\delta 1.34,4.1)$, carnitine ( $\delta 3.18)$ and choline ( $\delta 3.22)$ (Fig. 4 bottom). 


\section{Discussion}

In the present study, riboflavin status was assessed by the change of riboflavin content in plasma and liver, as well as EGRAC, a sensitive biochemical marker for riboflavin status (Hoey et al. 2009). It was found that plasma riboflavin content did not change significantly in response to acute hypoxia exposure, while the content of hepatic riboflavin was decreased significantly. It seems likely that plasma riboflavin level remains stable after acute hypoxia treatment partially via a compensatory process, in which more riboflavin is released into the bloodstream from the liver. However, EGRAC was elevated, suggesting that riboflavin status was compromised and more riboflavin was needed under acute hypoxia condition. This is in agreement with the results reported previously by Jiang et al. (1998), in which they demonstrated that riboflavin requirement was increased based on urinary riboflavin excretion in young volunteers exposed to the high altitude.

A large body of evidence indicates that hypoxia exposure leads to a disruption of energy metabolism, which is attributed to sympathetic activation at the early phase of exposure (Rafacho et al. 2013, Jun et al. 2012, Reinke et al. 2011). In the present study, it was noted that glucose metabolism switched from aerobic oxidation to anaerobic glycolysis as evidenced by increased production of pyruvate and lactate after acute hypoxia treatment. Increased plasma urea level suggested that protein catabolism was also enhanced. The elevated plasma level of $\beta$-hydroxybutyrate indicated that the ketogenesis was increased under acute hypoxia condition, which was resulted from both free fatty acid mobilization from white adipose tissue and decreased fatty acid oxidation (Jun et al. 2012). In addition, lower plasma carnitine level was detected after hypoxia exposure and this could be attributed to enhanced formation of acylcarnitines as demonstrated previously by Bruder and Raff (2010) in acute hypoxia treated young rats.

Riboflavin supplementation improved riboflavin status remarkably in hypoxic mice, especially in the hypoxia plus 8 times riboflavin supplemented group. Both plasma and hepatic contents of riboflavin were increased, whereas EGRAC was decreased significantly as compared to the hypoxia control. Meanwhile, plasma levels of pyruvate, free fatty acids and $\beta$-hydroxybutyrate were decreased significantly after riboflavin supplementation, suggesting that energy metabolism was partially improved. It is understandable because riboflavin in the form of $\mathrm{FAD}$ is a cofactor required by two critical enzymes in energy metabolism, i.e. pyruvate dehydrogenase and acyl-CoA dehydrogenase, which catalyze the decarboxylation of pyruvate and the first step in the $\beta$-oxidation of fatty acids, respectively (Powers 2003, Lienhart et al. 2013). Moreover, plasma carnitine was increased in response to riboflavin supplementation in a dose dependent manner. It is possible under acute hypoxic condition that the activity of acyl-CoA dehydrogenase is increased in response to riboflavin supplementation because it is sensitive to riboflavin status as reported previously by others (Hoppel et al. 1979, Sakurai et al. 1982, Ross and Hoppel 1987). As a result, the $\beta$-oxidation of fatty acids under acute hypoxia is restored to some extent and more acyl CoA is switched into $\beta$-oxidation. Therefore, more carnitine can be liberated from acylcarnitines during this process and recycled into the cytosol. It should be pointed out that carnitine not only is required for the transport of longchain fatty acids from the cytosol into the mitochondria, but also acts as an antioxidant and is effective in reducing hypoxia-induced oxidative stress and delaying muscle fatigue in rats as demonstrated by Dutta et al. (2008). Therefore, the protective action of carnitine against hypoxic damages, especially on mitochondria in hypoxic condition is worthy to be further investigated in detail.

Metabolomics is one of new "omics" disciplines and defined as "the quantitative measurement of metabolic responses to pathophysiological stimuli or genetic modification" (Nicholson et al. 1999). It has been proved to be efficient in probing endogenous metabolic perturbations induced by various endogenous and exogenous stimuli. Two major techniques, NMR and gas chromatography or liquid chromatography/mass spectrometry, are currently applied in metabolomic analysis. The multivariate data analysis methods, such as PCA and PLS-DA are frequently used to simplify metabolomic data processing in developing the metabolic profiles in response to different treatments (Smolinska et al. 2012, Wu et al. 2012, Lenz et al. 2003). In the present study, a ${ }^{1} \mathrm{H}$ NMR based metabolomic technique was used to investigate the effects of acute hypoxia and riboflavin supplementation on plasma metabolic profiling in hypoxic mice. The results obtained are basically consistent with the data from biochemical assays and confirm that acute hypoxia induces a significant change in plasma metabolic profiles in mice and an improvement is demonstrated upon riboflavin supplementation. For example, plasma levels of pyruvate, lactate and lipids 
were found to be increased, whereas carnitine decreased in response to acute hypoxia. Riboflavin intervention decreased plasma pyruvate level and increased carnitine level. It was also noted that plasma levels of some amino acids were changed after acute hypoxic treatment and riboflavin supplementation. It is explainable because the metabolism of some amino acids, such as alanine, glycine and glutamate, is closely related to the glucose homeostasis and detectable changes will be expected upon exposure to acute hypoxia and riboflavin supplementation (Sakami and Harrington 1963, Hue 1987). However, an obvious increase was also noted for plasma taurine after acute hypoxic exposure in this study. It is known that taurine acts as a cellular osmoregulator, as well as an antioxidant in vivo (Schaffer et al. 2000, Green et al. 1991). Previously, al-Bekairi (1989) also demonstrated that hypoxia caused a considerable increase in plasma and brain taurine in rats. It had been shown that hypoxia induced an osmotic stress and a large amount of taurine was released from the heart, which would contribute to the increase in plasma taurine (Schaffer et al. 2002). After riboflavin supplementation, increase in plasma taurine was reduced, implying that cellular osmotic stress was partially ameliorated. Furthermore, an increase of plasma choline was detected after acute hypoxia and a decrease noted after riboflavin supplementation. Jenden and Scremin also demonstrated that hypoxia induced an increase in arterial blood choline, which was resulted from parallel decreases in choline production and clearance. They postulated that increased blood choline level might be helpful in preventing the cerebral loss of choline under acute hypoxia condition (Jenden and Scremin 1995, Scremin and Jenden 1992).

In conclusion, this study demonstrates that riboflavin requirement is increased under acute hypoxia condition and riboflavin supplementation is effective partially in improving energy metabolism in hypoxic mice. The ${ }^{1} \mathrm{H}$ NMR based metabolomic analysis further provides supportive data. Meanwhile, more information related to the changes of other metabolites is also obtained. Although a number of important biochemical markers related to energy metabolism in plasma were determined, we are aware that the current study is limited. The levels of some critical metabolites and activities of flavin-dependent enzymes, such as pyruvate dehydrogenase and acyl-CoA dehydrogenase, are not measured in different tissues, though supportive data are available in literature. Further studies are warranty to investigate the effects of riboflavin on the activities of critical enzymes and metabolites involved in energy metabolism in different tissues and elucidate underlying molecular mechanisms in acute hypoxia.

\section{Conflict of Interest}

There is no conflict of interest.

\section{Acknowledgements}

This study is supported financially by a grant from the National Natural Science Foundation of China (NO 30872097). We thank Professor Xianzhong Yan and Dr Bo Sun from the NMR Laboratory, National Center of Biomedical Analysis for expert assistance in ${ }^{1} \mathrm{H}$ NMR analysis and data processing.
Abbreviations
ANOVA: analysis of variance
CPMG: Carr-Purcell-Meiboom-Gill
EGRAC: erythrocyte glutathione activation coefficient
FAD: flavin adenine dinucleotide
FIDs: free reduction decays
FMN: flavin mononucleotide
FW: fresh weight
LED: longitudinal eddy-current delay
MTHFR: methylenetetrahydrofolate reductase
NMR: nuclear magnetic resonance
OSC: orthogonal signal correction
PCA: principal components analysis
PLS-DA: partial least squares-discriminant analysis
TSP: 3-(trimethylsilyl)-propionic-(2,2,3, 3,-d4)-acid sodium

\section{References}

AL-BEKAIRI AM: Effect of hypoxia and/or cold stress on plasma and brain amino acids in rat. Res Commun Chem Pathol Pharmacol 64: 287-297, 1989.

BRADY PS, HOPPEL CL: Hepatic peroxisomal and mitochondrial fatty acid oxidation in the riboflavin-deficient rat. Biochem J 229: 717-721, 1985.

BRUDER ED, RAFF H: Cardiac and plasma lipid profiles in response to acute hypoxia in neonatal and young adult rats. Lipids Health Dis 9: 3-8, 2010. 
BUTTERFIELD GE: Nutrient requirements at high altitude. Clin Sports Med 18: 607-621, 1999.

DUTTA A, RAY K, SINGH VK, VATS P, SINGH SN, SINGH SB: L-carnitine supplementation attenuates intermittent hypoxia-induced oxidative stress and delays muscle fatigue in rats. Exp Physiol 93: 1139-1146, 2008.

GREEN TR, FELLMAN JH, EICHER AL, PRATT KL: Antioxidant role and subcellular location of hypotaurine and taurine in human neutrophils. Biochim Biophy Acta 1073: 91-97, 1991.

GU CF, CHEN YZ, WANG ZY, ZHAN GY, GAO LX: The application of blood glutathione reductase activation coefficient in nutrition survey. (in Chinese) Acta Nutr Sinica 4: 349-352, 1982.

GUILLAND JC, KLEPPING J: Nutritional alterations at high altitude in man. Eur J Appl Physiol Occup Physiol 54: 517-523, 1985.

GUO CJ, YANG JJ, WEI JY, XU J, LI YF, XIE YZ: Experimental evaluation of an acute hypoxia endurance enhancing nutritional supplement. (in Chinese) Chin J High Altitude Med 14: 1-4, 2004.

HOEY L, MCNULTY H, STRAIN JJ: Studies of biomarker responses to intervention with riboflavin: a systematic review. Am J Clin Nutr 89 (Suppl): 1960S-1980S, 2009.

HOPPEL CL, DIMARCO JP, TANDLER B: Riboflavin and rat hepatic cell structure and function. Mitochondrial oxidative metabolism in deficiency states. J Biol Chem 254: 4164-4170, 1979.

HUE L: Gluconeogenesis and its regulation. Diabetes Metab Rev 3: 111-126, 1987.

JENDEN DJ, SCREMIN OU: Effects of hypoxia and hypercapnia on whole body release and clearance of choline. Am J Physiol 268: R1520-R1525, 1995.

JIANG BQ, HUANG GR, YANG JJ, SHI YG, WEI N, CAO FW: Study of riboflavin requirement for the youth at the beginning stage of entering high altitude. (in Chinese) Acta Nutr Sinica 20: 286-289, 1998.

JUN JC, SHIN M, YAN Q, BEVANS-FONTI S, POULE J, DRAGER LF, POLOTSKY VY: Acute hypoxia induces hypertriglyceridemia by decreasing plasma triglyceride clearance in mice. Am J Physiol 303: E377-E388, 2012.

LENZ EM, BRIGHT J, WILSON ID, MORGAN SR, NASH AFP: A ${ }^{1} \mathrm{H}$ NMR-based metabonomic study of urine and plasma samples obtained from healthy human subjects. J Pharm Biomed Anal 33: 1103-1115, 2003.

LIENHART WD, GUDIPATI V, MACHEROUX P: The human flavoproteome. Arch Biochem Biophys 535: 150-162, 2013.

MCNULTY H, DOWEY LE RC, STRAIN JJ, DUNNE A, WARD M, MOLLOY AM, MCANENA LB, HUGHES JP, HANNON-FLETCHER M, SCOTT JM: Riboflavin lowers homocysteine in individuals homozygous for the MTHFR 677C $\rightarrow$ T polymorphism. Circulation 113: 74-80, 2006.

NDAW S, BERGAENTZLE M, AOUDE-WERNER D, HASSELMANN C: Extraction procedures for the liquid chromatographic determination of thiamin, riboflavin and vitamin $\mathrm{B}_{6}$ in foodstuffs. Food Chem 71: 129-138, 2000.

NICHOLSON JK, LINDON JC, HOLMES E: 'Metabonomics': understanding the metabolic responses of living systems to pathophysiological stimuli via multivariate statistical analysis of biological NMR spectroscopic data. Xenobiotica 29: 1181-1189, 1999.

POWERS HJ: Riboflavin and health. Am J Clin Nutr 77: 1352-1360, 2003.

RAFACHO A, GONCALVES-NETO LM, FERREIRA FBD, PROTZEK AOP, BOSCHERO AC, NUNES EA, ZOCCAL DB: Glucose homeostasis in rats exposed to acute intermittent hypoxia. Acta Physiol 209: 77-89, 2013.

REEVES PG, NIELSEN FH, FAHEY GC: AIN-93 purified diets for laboratory rodents: final report of the American Institute of Nutrition Ad Hoc Writing Committee on the reformulation of the AIN-76A rodent diet. J Nutr 123: 1939-1951, 1993.

REINKE C, BEVANS-FONTI C, DRAGER LF, SHIN MK, POLOTSKY VY: Effects of different acute hypoxic regimens on tissues oxygen profiles and metabolic outcomes. J Appl Physiol 111: 883-890, 2011.

ROSS NS, HOPPEL CL: Acyl-CoA dehydrogenase activity in the riboflavin-deficient rat. Effects of starvation. Biochem J 244: 387-391, 1987.

SAKAMI W, HARRINGTON H: Amino acid metabolism. Annu Rev Biochem 32: 355-398, 1963. 
SAKURAI T, MIYAZUWA S, FURUTA S, HASHIMOTO T: Riboflavin deficiency and beta-oxidation systems in rat liver. Lipids 17: 598-604, 1982.

SCHAFFER SW, TAKAHASHI K, AZUMA J: Role of osmoregulation in the actions of taurine. Amino Acids 19: 527$546,2000$.

SCHAFFER SW, PASTUKH V, SOLODUSHKO V, KRAMER J, AZUMA J: Effect of ischemia, calcium depletion and repletion, acidosis and hypoxia on cellular taurine content. Amino Acids 23: 395-400, 2002.

SCREMIN OU, JENDEN DJ: Effects of hypoxia on choline exchange among organs. J Neurochem 59: 906-914, 1992.

SIMON-SCHNASS IM: Nutrition at high altitude. J Nutr 122: 778-781, 1992.

SMOLINSKA A, BLANCHET L, BUYDENS LW, WIJMENGASS SS: NMR and pattern recognition methods in metabolomics: from data acquisition to biomarker discovery: a review. Anal Chim Acta 750: 82-97, 2012.

WANG W, HA Z, ZHANG F, ZHANG XZ, CUI JH, MA Y, BAI GS, XING GX: Effects of acetazolamide and Weikang tablet on physical performance in young adults at high altitude. (in Chinese) Med $J$ National Defending Forces Southwest China 15: 23-24, 2005.

WEI JY, GUO CJ, XU J, YANG JJ, PANG W, XU QS: Determination of riboflavin, FMN and FAD in human plasma and erythrocytes by high performance liquid chromatography. (in Chinese) Acta Nutr Sinica 28: 79-82, 2006.

WU JQ, GAO WN, WEI JY, YANG JJ, PU LL, GUO CJ: Quercetin alters energy metabolism in swimming mice. Appl Physiol Nutr Metab 37: 912-922, 2012. 